\title{
(t)
}

\section{NOTAS SOBRE A QUESTÃO AGRÁRIA HAITIANA}

\author{
Notes on Haitian Agrarian Question
}

\section{Thalles Gomes ${ }^{1}$}

\section{RESUMO}

Partindo da interpretação do subdesenvolvimento latino-americano construída por Ruy Mauro Marini, o artigo investiga os momentos-chave da trajetória histórica da questão agrária haitiana em que se evidencia o papel determinante da interferência do Capitalismo internacional em conluio com setores da burguesia nacional na perpetuação da dependência socioeconômica do Haiti.

\section{PALAVRAS-CHAVE}

Questão Agrária. Haiti. Capitalismo internacional. Dependência.

\section{ABSTRACT}

Based on the interpretation of Latin American underdevelopment built by Ruy Mauro Marini, this article investigates the key moments in the historical trajectory of the Haitian agrarian question in which it's evident the determinant role of the international capitalism interference in collusion with sectors of the national bourgeoisie in the perpetuation of socio-economic dependence of Haiti.

\section{KEYWORDS}

Agrarian question. Haiti. International capitalism. Dependence.

\footnotetext{
${ }^{1}$ Graduado em Direito pela Universidade Federal de Alagoas (UFAL). Formado em Cinema, com especialização em Montagem e Edição de Imagem e Som, pela Escola de Cinema Darcy Ribeiro (RJ). Durante o ano de 2010, atuou no Haiti como correspondente estrangeiro pelo jornal Brasil de Fato. Atualmente, é pesquisador do grupo de pesquisas Modos de Produção e Antagonismos Sociais (UnB), e professor da Faculdade Anhanguera Osasco (SP). E-mail: <gomescamello@gmail.com>.
} 


\section{INTRODUÇÃO}

Bééé. É a primeira coisa que se ouve quando se chega a uma cidade ou vilarejo no campo haitiano. Não se sabe bem de onde vem tal som e nunca se descobre quem o pronuncia. Será uma criança? Um jovem? Um velho feirante? Uma camponesa das montanhas? Não se sabe. Mas ele está lá e, se você for um blan, ele te acompanhará por onde você for.

Blan significa branco na língua local, o kreyòl. E, apesar de não haver nenhum branco entre nós, era assim que todos nos chamavam.

Algo parecido com gringo, mas carregando carga pejorativa ainda maior, blan é o termo usado para designar todos os estrangeiros, sejam eles brancos, amarelos ou negros. E, no Haiti, não há nada mais estranho que ser estrangeiro.

Fruto da única revolução de escravos vitoriosa da história, derrotando os exércitos mais poderosos de sua época, a independência do Haiti, em 1804, não livrou a pequena ilha caribenha da constante interferência e presença estrangeira.

Uma breve mirada pela trajetória haitiana revela que, desde a impagável dívida da independência imposta pelos franceses na primeira metade do século XIX, passando por vinte anos de ocupação estadunidense no início do século XX, uma sangrenta Ditadura levada a cabo pelos Duvalier sob os auspícios das potências ocidentais e a mais recente ocupação das forças armadas das Nações Unidas fizeram com que o estrangeiro fosse visto em território haitiano sob a égide da polida desconfiança - quando não, do ódio e do desprezo.

Ser estrangeiro no Haiti não significava lidar apenas com diferenças culturais, praxe no contato entre distintos. Havia uma herança dolorosa que todo blan despertava com sua presença - ainda mais quando se compartilhava o mesmo gênero e faixa etária dos soldados da Missão das Nações Unidas para a Estabilização do Haiti (MINUSTAH), presente no Haiti desde 2004. Os mesmos soldados que, no início da ocupação, roubaram cabritos dos camponeses. Por isso o bééé como cartão de visita para todo blan que atravessava o campo haitiano. Kabrit vòlè. Ladrão de cabrito. 
Desconstruir essa herança era o ponto de partida de todos os estrangeiros que aportaram no Haiti após o terremoto de 12 de janeiro de 2010. Os quarenta e dois segundos de tremor de terra, que mataram mais de trezentas mil pessoas, deixando 1,5 milhões de desabrigados e destruindo o equivalente a $120 \%$ do Produto Interno Bruto (PIB) haitiano (CHALMERS, 2010), transformaram a pequena ilha no país da piedade alheia, local de peregrinação preferido para políticos e personalidade de todo mundo expressarem sua compaixão. Sobrevoando as ruínas em seus helicópteros, declaravam com voz embargada suas condolências perante as câmeras de televisão e reafirmavam compromissos de ajuda às vítimas do terremoto.

Boa parte dessa compaixão, obviamente, tinha prazo de validade e migrou junto com as manchetes dos jornais para a próxima catástrofe mundial da vez. Houve, porém, os que permaneceram - e que se somaram aos que já estavam em território haitiano antes do terremoto.

Lutando contra a herança dolorosa que sua presença por si só despertava, a única saída para os blans era incorporar-se o máximo possível ao dia a dia dos haitianos, vivenciando inteiramente seu cotidiano, para sentir na pele suas dificuldades e absorver seus traumas. Só assim seria possível compreender o ser haitiano e se somar à sua busca por dias melhores.

Uma atitude nobre, mas falha. O motivo é simples: por mais que tente, um blan nunca será um haitiano. Convivendo nas casas humildes dos camponeses, trabalhando no campo, alimentando-se parcamente, dormindo entre as ruínas ou percorrendo as ruelas inseguras de Porto Príncipe, o máximo que o estrangeiro conseguirá será experimentar, por um momento, a sensação de ser haitiano. $\mathrm{E}$ há muita diferença entre a experiência e a sentença de vida.

Não há fatalismo nesta afirmação. Apenas a constatação de que ao estrangeiro, mesmo quando mergulhado no mais profundo da vida haitiana, resta sempre a remota perspectiva de retorno à normalidade além-mar. Em última instância, tínhamos o poder de acabar com tudo aquilo embarcando num avião. Acreditar, dessa forma, que poderíamos viver na pele ou absorver os traumas do ser haitiano é o mesmo que supor ser possível vivenciar uma tentativa de suicídio 
pulando de bungee jumping. A consciência derradeira da corda amarrada aos pés torna a desesperança mais suportável, porque finita.

Todo blan sabe disso, assim como todo haitiano. E é essa consciência mútua que transforma a relação entre os dois num eterno - e latente - conflito. Suponho que, para o haitiano, quando se trata de um soldado estrangeiro, arquétipo do invasor, a relação se torne mais simples - afinal, nada mais instintivo que a repulsa ao intruso armado. Mas o que acontece quando, imerso na miséria e exploração, o blan lhe estende a mão, dizendo entender como ele se sente?

É sob essa ressalva que estas linhas devem ser lidas. Trata-se da investigação de um estrangeiro, um blan, um kabrit vòlè, que busca compreender a conjuntura atual do Haiti a partir da perspectiva camponesa.

\section{DA COLÔNIA MAIS PRÓSPERA À NAÇÃO MAIS POBRE}

Com uma população de 10 milhões de habitantes e um território pouco menor que o estado de Alagoas, o Haiti é hoje a nação mais pobre do continente americano. Como afirma a socióloga Suzy Castor:

São conhecidos os índices que fazem do Haiti o país mais subdesenvolvido do continente, o modelo ameaçador para não seguir: cerca de $56 \%$ da população está abaixo da linha da pobreza absoluta; uma expectativa de vida de 58,1 anos; $39 \%$ de analfabetismo; $49 \%$ de crianças sem escolarização; $75 \%$ da população sem acesso à água potável. Nas áreas rurais, somente $13,1 \%$ dos habitantes chega a satisfazer adequadamente suas necessidades de alimentos (CASTOR, 2008, 15).

Apesar de ser uma sociedade essencialmente rural, com $66 \%$ de seus 10 milhões de habitantes vivendo no campo, as famílias camponesas não têm acesso nem a terra nem a serviços públicos básicos, como água encanada e energia elétrica, o que faz com que o país importe $50 \%$ dos alimentos que consome.

Mas não foi sempre assim. No final do século XIX, o Haiti era a colônia mais próspera das Américas, responsável por $2 / 3$ do comércio exterior da França (JAMES, 2000). A pergunta fundamental a ser feita, então, é esta: "Como é que um país sai da condição de colônia mais próspera das Américas para se tornar o país mais pobre do continente?". 
Lembrado pela comunidade internacional apenas nos momentos de tragédia ou nas ocupações militares, a miséria que assola o Haiti não pode ser explicada como mero fruto de catástrofes naturais ou turbulências políticas. Fenômenos naturais e instabilidade política podem agravar, mas não criam a miséria. E, ao menos que se compartilhe da opinião do cônsul geral do Haiti em São Paulo, o senhor George Samuel Antoine, segundo a qual "[...] o africano em si tem maldição, todo lugar que tem africano lá tá fudido” (ANTOINE, 2010), tampouco é possível compreender a situação partindo de argumentos racistas ou oriundos da intolerância religiosa.

Se a questão é mais complexa do que aparece à primeira vista, talvez seja o caso de descartar as explicações simplórias que não conseguem superar a superfície dos fatos e ir ao fundo da questão. Buscar a essência do problema para depois voltar à superfície com os elementos adequados para decifrá-la.

Um ponto de partida possível para essa busca é a afirmação do economista brasileiro Ruy Mauro Marini em seu ensaio Subdesenvolvimento e Revolução: "[...] a história do subdesenvolvimento latino-americano é a história do desenvolvimento do sistema capitalista mundial" (MARINI, 1974, p.1). O que Marini quis dizer com isso? Que desenvolvimento e subdesenvolvimento são duas faces da mesma moeda. O subdesenvolvimento não é uma etapa rumo ao desenvolvimento, mas condição necessária para a existência de uma minoria desenvolvida.

Seguindo essa linha de raciocínio, a pobreza e miséria haitianas não podem ser encaradas como um acidente de percurso fruto de catástrofes naturais ou má administração do estado, mas consequência do processo de desenvolvimento do sistema capitalista.

Portanto, para responder por que a colônia mais próspera se transformou na nação mais pobre do continente é preciso analisar sua trajetória socioeconômica e as relações de dependência estrangeira constituídas ao longo de sua história. Em outras palavras, descobrir qual a função destinada ao Haiti no processo de desenvolvimento do Capitalismo mundial.

De fato, há momentos-chave na formação histórica haitiana em que esta contradição fica mais evidente e se percebe com mais 
facilidade como o desenvolvimento do Capitalismo internacional interfere diretamente no (não) desenvolvimento do Haiti.

Sendo um país essencialmente agrário, o campo é, obviamente, o cenário privilegiado deste conflito e, consequentemente, ponto de partida da análise. Isso porque, em toda a trajetória histórica haitiana, o campo sempre se constituiu como o fiel da balança para determinar os avanços e retrocessos da sociedade haitiana.

Entretanto, antes de abordar esses momentos-chave, faz-se necessária uma observação. As linhas que seguem buscam desvelar a interferência do Capitalismo internacional na perpetuação da dependência socioeconômica haitiana. Todavia, não se trata de uma via de mão única. Sem a conivência e apoio de parcelas da burguesia haitiana, essa interferência não alcançaria tão facilmente seus objetivos. Se a atuação da burguesia nacional não é devidamente ressaltada e problematizada ao longo do artigo, isso se deve aos limites da investigação de um blan estrangeiro.

\section{INDEPENDÊNCIA}

O primeiro destes momentos-chave se deu no próprio processo de independência do Haiti. Os treze anos (1791 a 1804) da luta revolucionária dos escravos haitianos que derrotou as três maiores potências bélicas da época - Espanha, Inglaterra e França - não significaram apenas um conflito contra o jugo colonial. Diferente do que se passou em outros países do continente, no Haiti, a luta foi essencialmente antiescravista. 'Nós realizamos duas rupturas', esclarece Camille Chalmers, professor da Faculdade de Ciências Humanas da Universidade Estatal do Haiti e coordenador da Plateforme Haïtienne de Plaidoyer pour un Développement Alternatif (PAPDA):

'Uma ruptura com as metrópoles coloniais e também uma ruptura nas relações sociais internas, através da abolição da escravidão e do intento de criar uma economia autocentrada nas necessidades básicas da população' (CHALMERS, 2010). ${ }^{2}$

\footnotetext{
${ }^{2}$ Todas as citações de Camille Chalmers presentes neste artigo foram retiradas de entrevista concedida ao autor em Porto Príncipe/Haiti, no dia 17 de setembro 2010 (CHALMERS, 2010).
} 
Ao conquistarem a abolição da escravidão, em 1793, os revolucionários haitianos destruíram um dos pilares do sistema de produção vigente nas Américas até então, o Plantation. A mão-de-obra escrava, que, em 1789 , representava $87 \%$ da população da colônia (CAUVIN, 1975), era pré-requisito necessário para garantir a viabilidade de um sistema de produção agrícola baseado no monocultivo para exportação. Vale lembrar que os Estados Unidos só acabaram com a escravidão em suas terras setenta anos depois, enquanto o Brasil só o fez passados noventa e cinco anos.

Mas não foi só a escravidão o alvo de ataque do processo revolucionário haitiano. A propriedade da terra também foi colocada em xeque. Porque, para além da sua própria libertação, os escravos reivindicavam a redistribuição das terras do país para quem nela, de fato, vivia e trabalhava.

Tanto é que, em dois de janeiro de 1804, um dia após proclamarem a independência do país, Jean Jacque Dessalines e os generais do exército revolucionário haitiano publicaram a primeira lei da nação determinando a nacionalização de todas as terras e plantações que estavam nas mãos dos estrangeiros.

O fim da escravidão somado a uma política agrária que priorizava o abastecimento interno eram golpes ousados demais contra a divisão social do trabalho e o arranjo geopolítico da época. A revolução industrial estava em pleno desenvolvimento na Europa e o papel reservado às colônias americanas era fornecer matérias-primas e consumir os produtos manufaturados europeus. Tamanha ousadia, portanto, não sairia impune e não tardou para que as potências ocidentais lançassem sua represália contra a revolução haitiana.

Refletindo sobre esse período, Camille Chalmers comenta que, com o assassinato de Dessalines, em 1806,

Constitui-se um estado oligárquico, um estado ao redor de novas classes dominantes que construíram seu poder marginalizando sistematicamente a classe camponesa que havia realizado a revolução antiescravista. Dessa forma, trata-se de um estado que se constitui de maneira totalmente oposta à nação e que define seus interesses sobre o intercâmbio comercial com o estrangeiro e com o mercado capitalista (CHALMERS, 2010). 
O intuito desse estado, então, é a de rearticular a economia de Plantation. "Mas é impossível regressar à economia de Plantation quando já não há mais escravidão", observa Chalmers (2010), "[...] e é essa tensão que explica o bloqueio do desenvolvimento do país, pois esta cisão entre Estado e nação nunca foi resolvida" (CHALMERS, 2010).

Essa guinada conservadora no processo de formação haitiano não foi por acaso. As potências internacionais tiveram atuação determinante nesse retrocesso. Os Estados Unidos, além de não reconhecerem a independência haitiana, impuseram-lhe um embargo econômico que se estendeu por seis décadas. Mesma atitude tomada pela França. Isolado politicamente e impossibilitado de comercializar com outras nações, o Haiti se viu obrigado a pagar uma dívida da independência reclamada pelo governo francês para repor as perdas financeiras com o fim da escravidão e da exploração colonial. De 1825 a 1947, o Haiti pagou à França 150 milhões de francos, o equivalente a atuais 20 bilhões de dólares.

Diante desse quadro, a saída encontrada pelo estado haitiano para lidar com a questão agrária no país foi a distribuição de terras entre as oligarquias ligadas às próprias estruturas estatais e ao alto escalão do exército. É daí que surge a palavra grandon, junção de gran (grande) e don (doação), que até hoje designa os latifundiários em kreyòl.

“Estamos diante de uma situação onde há um bloqueio criado por essa ruptura do Estado com a população, com a massa camponesa e da relação de dependência deste mesmo Estado com respeito às potências imperialistas", conclui Chalmers (2010). "Desde então, jamais houve uma política agrária verdadeira no país. Podemos dizer que a questão agrária jamais foi objeto de reflexão, de definição e de aplicação política", completa Gerald Mathurin (2010), ex-ministro da Agricultura (1996/1997) e atual coordenador da organização camponesa Kòdinasyon Rejyonal Òganizasyon Sidès (KROS) 3 .

3 Todas as citações de Gerald Mathurin presentes neste artigo foram retiradas de entrevista concedida ao autor em Jakmél/Haiti, no dia 20 de julho de 2010. 


\section{PRIMEIRA OCUPAÇÃO}

"O problema maior de tudo isso é que algumas dessas pessoas, com um pouco de recurso e educação, pensam que são tão boas quanto nós" (JONHSON, 1920, p. 18, grifo nosso).

Essa foi a opinião expressa por um oficial do exército estadunidense sobre o povo haitiano. Quem a ouviu e divulgou foi outro norte-americano: James Weldon Johnson, membro da National Association for the Advancement of Colored People.

Corria o ano de 1920 e Johnson (1920) visitava o Haiti para entender quais as consequências da ocupação militar norte-americana na pequena ilha caribenha, que já perdurava cinco anos. Suas impressões foram publicadas numa série de reportagens do jornal The Nation, depois compiladas num folheto intitulado Self-Determining Haiti e constituem um importante documento histórico para compreender os motivos e resultados de outro momento-chave na formação histórica haitiana: a primeira ocupação dos EUA no Haiti, que durou de 1915 a 1934.

Johnson (1920) nos recorda que, em 28 de julho de 1915, 20 mil marines estadunidenses desembarcaram e ocuparam Porto Príncipe. Sua justificativa oficial era de que tal intervenção se baseava em objetivos puramente humanitários, já que um trágico golpe de estado havia causado a deposição e morte do Presidente Vilbrun Guillaume Sam, além da execução de prisioneiros políticos. O governo estadunidense se viu, então, obrigado ocupar o país e manter suas tropas em território haitiano para pacificar o país e preservar a ordem.

A história oficial não divulgou, entretanto, que o National City Bank of New York era o principal investidor dos Estados Unidos no Haiti à época, exercendo total controle sobre o Banco Nacional do Haiti ao conceder empréstimos a juros exorbitantes para que o governo haitiano pudesse pagar seus débitos junto aos próprios bancos norte-americanos e franceses, numa espiral sem fim de endividamento que se iniciara com a imposição da Dívida da Independência em 1825.

Os livros de história tampouco divulgam que, temendo a influência de outras potências europeias - a Alemanha, por exem- 
plo, cujo capital se expandia cada vez mais na ilha -, o governo dos Estados Unidos, sempre em parceria com o National City Bank, tentava submeter o Haiti a uma intervenção "pacífica” já um ano antes do desembarque dos marines.

É por isso que, de acordo com Johnson, a queda de Guillaume e o massacre de prisioneiros políticos não constituíram a causa da ocupação norte-americana. Foram apenas a oportunidade esperada para uma intervenção que já se planejava.

Com o desembarque dos marines norte-americanos, em julho de 1915, exército haitiano foi desarmado e o Palácio Nacional transformado em quartel general da ocupação. Depois de selecionarem um novo presidente para o país, foram tomadas todas as providências necessárias para que o governo haitiano repassasse todas as finanças do Haiti para o controle dos americanos. Com isso, todos os fundos e impostos coletados durante a ocupação seriam depositados e geridos pelo National City Bank of New York. Em outras palavras, um governo do, para e pelo National City Bank.

Mas, mesmo com um acordo que praticamente despiu o Haiti de sua soberania, a Constituição da República ainda apresentava alguns empecilhos. Fechado o Congresso, as forças de Ocupação convocaram um plebiscito popular para a aprovação da Nova Constituição. Sob os rifles dos marines, o resultado do plebiscito foi unânime pela aprovação das modificações. A principal delas foi a retirada do dispositivo constitucional que proibia estrangeiros de adquirirem terras em território haitiano. Com isso, se abriram as portas para que grandes plantações de cana-de-açúcar, café e sisal passassem para as mãos de empresas estadunidenses, além das concessões para a exploração mineira de bauxita, cobre e ouro.

Mas nem só de imposição é feita uma ocupação. Ao governo dos Estados Unidos era preciso mostrar que, além da pacificação do país, a presença estadunidense traria progresso e desenvolvimento à pequena ilha. E o carro-chefe da publicidade americana, nesse período, foi a construção da rodovia que ligaria a capital Porto Príncipe à cidade de Cabo Haitiano, no extremo norte do País.

Principal obra de infraestrutura realizada pela ocupação norte-americana, a construção dessa rodovia tinha como objetivo de 
fundo criar um corredor militar que garantisse o transporte dos suprimentos e das tropas americanas de um extremo a outro da ilha.

Para recrutar a mão-de-obra necessária à construção da rodovia, os marines e sua engenharia de ponta decidiram ressuscitar uma antiga lei haitiana, o corvée.

De acordo com o corvée, cada cidadão haitiano deveria trabaIhar um determinado número de dias para ajudar na manutenção das rodovias públicas. Na época em que esta lei esteve em vigor, nos primeiros anos pós-independência, o governo haitiano nunca exigiu que os cidadãos trabalhassem em rodovias fora de suas próprias comunidades e num número de dias que não ultrapassasse três a cada ano.

Não foi o que a ocupação fez. Ao contrário, instaurou um verdadeiro reino de terror entre os camponeses haitianos, recrutando homens onde quer que os encontrasse. Nas palavras de Johnson (1920, p. 13-14):

Pelo dia ou pela noite, enquanto trabalhavam em suas pequenas lavouras com suas famílias ou mesmo quando caminhavam inocentemente pelas estradas, os haitianos foram convocados e levados à força por meses a fio para trabalhar nos rincões mais distantes do país, sem que nenhum parente ou familiar recebesse qualquer informação de seu paradeiro. Os que protestavam eram torturados. Os que tentavam escapar eram abatidos a tiro.

Devido a essa prática digna dos tempos mais crus da escravidão, muitos camponeses fugiram de suas terras e foram se esconder nas montanhas. Outros decidiram se rebelar. Os camponeses que se rebelaram e se armaram para enfrentar os abusos da ocupação americana foram chamados de "bandidos" pelo exército ocupante, mas entre a população haitiana eles eram reconhecidos por outro nome: os Cacos, liderados por Charlemagne Péralte (BANDITS..., 1919).

Natural de Hinche, região central do Haiti, Péralte ocupava o cargo de chefe militar da cidade de Léogane quando os marines estadunidenses invadiram o país em julho de 1915. Contrário à rendição e impedido de lutar, Péralte foi obrigado a se refugiar em sua cidade 
natal para cuidar das terras de sua família. Em 1917, acusado de ajudar camponeses que se rebelaram contra a prática do corvée, foi sentenciado a cinco anos de trabalhos forçados. Logo consegue escapar e, no mesmo ano, junto com um grupo de camponeses rebeldes, dá inicio a uma resistência armada contra as tropas de ocupação estrangeira. Era o início da Guerrilha dos Cacos.

Em pouco menos de um ano, os Cacos já ultrapassavam a casa dos milhares e haviam declarado um governo provisório no Norte do Haiti. Em cartas publicadas durante o ano de 1919, Péralte conclama (BANDITS..., 1919):

Povo do Haiti, em breve um dia como o $1^{\circ}$ de Janeiro de 1804 surgirá. Por quatro anos a Ocupação tem nos insultado constantemente. Cada manhã ela nos traz uma nova ofensa. [...] Hoje nós perdemos a paciência e reclamamos nossos direitos, direitos ignorados pelos inescrupulosos Americanos, que destroem nossas instituições e privam a população haitiana de todos seus recursos, devorando nosso nome e nosso sangue. Por quatro anos, cruéis e injustos lanques trouxeram ruína e desesperança para nosso território [...]. Nós estamos preparados para sacrificar tudo para libertar o Haiti e estabelecer aqui os princípios afirmados pelo próprio Presidente [dos Estados Unidos] Wilson: os direitos e a soberania das pequenas nações. Notem que, se as tropas americanas seguirem suas próprias leis, elas não têm nenhum direito de lutar contra nós (BANDITS..., 1919, tradução nossa).

Em resposta a Guerrilha dos Cacos, os marines estadunidenses organizaram uma feroz contrainsurgência, utilizando inclusive aviões de guerra, que arrasou vilarejos, destruiu comunidades inteiras e matou milhares de haitianos.

De acordo com dados dos próprios marines, somente no período de março a novembro de 1919, mais de 3.250 "bandidos" foram assassinados. Dentre eles, o próprio Charlemagne Péralte que, traído por um de seus oficiais, foi assassinado a sangue frio por soldados americanos no dia 31 de outubro de 1919.

Benoit Batraville, que tomou o lugar de Charlemagne Péralte como líder dos Cacos, resistiu por mais um ano, até que foi as- 
sassinado em maio de 1920, levando com ele o último foco de resistência da Guerrilha dos Cacos.

Os 21 anos de ocupação norte-americana criaram um estado totalmente dependente e um exército que obedecia às ordens que vinham diretamente do Departamento de Estado em Washington. "Trata-se de uma substituição da dependência ante as potências europeias pela dependência direta aos Estados Unidos, em condições onde se modifica totalmente o jogo político interno, marginalizando ainda mais o campesinato", comenta Camille Chalmers (2010). A brutal repressão à guerrilha dos Cacos é exemplo dessa marginalização. "Entretanto", ressalva Camille, "ainda não se compreendeu que o pequeno campesinato e a pequena produção da agricultura têm sido o elemento básico da resistência haitiana, permitindo que o Haiti, apesar de todas essas condições, tenha obtido uma autossuficiência em termos de cereais até o ano de 1972" (CHALMERS, 2010).

E, para entender porque precisamente o ano de 1972, será preciso desvendar novamente as correlações entre a conjuntura local haitiana e o desenvolvimento do Capitalismo internacional.

\section{NEOLIBERALISMO}

Depois de acirradas eleições, o médico François Duvalier chegou à presidência haitiana em 1957. Representando a oligarquia negra e contando com o apoio da pequena burguesia haitiana, o governo de Papa Doc não tardou em demonstrar sua verdadeira faceta e instalar novos métodos de dominação política baseados em um verdadeiro terrorismo de estado. Nas palavras de Suzy Castor, "[...] uma ditadura de caráter personalista com rasgos fascitoides e um sistema de poder baseado na violência institucionalizada" (CASTOR, 1984, p. 114).

Setores progressistas foram torturados, presos, exilados e assassinados pelo maquinário de terror e repressão instalado pela Ditadura duvalierista. Igreja, poder judiciário e os meios de comunicação foram subjugados, e o exército nacional neutralizado com a criação dos Tontons Macoutes, corpo repressivo a serviço exclusivo do presidente. Estima-se que a regime duvalierista tenha assassinado mais de 30 mil haitianos e haitianas. 
A consolidação do duvalierismo no Haiti contou com o apoio do capital internacional. "No novo contexto surgido na América Latina a partir da Revolução Cubana”, observa Castor, “[...] o imperialismo norte-americano estreitou sua aliança com o duvalierismo, proporcionando-lhe ajuda política, econômica, militar e policial, permitindo uma maior integração de todos os aspectos da vida nacional ao sistema de dominação" (CASTOR, 1984, 115). De fato, a ditadura Duvalierista, ao contar com o suporte da burguesia nacional submissa aos interesses imperialistas, criou as condições ideais para o avanço dos investimentos capitalistas estrangeiros no Haiti.

Com a morte de François Duvalier, em 1971, seu filho Jean-Claude Duvalier assumiu o poder prometendo a modernização do país, o que, na prática, significou o aumento dos requintes de crueldade das forças repressoras conjugado a um relativo e breve desenvolvimento econômico fruto dos altos preços do café, da instalação das indústrias maquiladoras e do incremento dos investimentos estrangeiros no país. No entanto, no caminho da Ditadura de Baby Doc e sua "modernização" havia a crise econômica que afetou todo o sistema capitalista nos anos 70 e trouxe consequências nefastas para o Haiti e para todos os países latino-americanos.

Os anos 70 foram marcados pelo que os economistas marxistas definem como crise cíclica do Capitalismo, fruto das contradições existentes dentro do próprio sistema capitalista. Esta crise surgiu quando a superprodução de capital foi incapaz de continuar obtendo os mesmos níveis de lucratividade anteriores.

As respostas encontradas pelo sistema capitalista internacional para recuperar seus lucros foram, basicamente, o aumento da transferência de recursos da periferia subdesenvolvida para as potências centrais, e a expansão e abertura de novos mercados consumidores. Essas medidas, que tiveram seu início nos anos 70, perpassaram a década de 80 e tiveram seu auge nos anos 1990, ficaram conhecidas como políticas neoliberais e atingiram em cheio a economia e a sociedade haitiana.

A primeira dessas consequências foi o aumento exponencial da dívida externa. De U\$ 28,4 milhões, em 1971, a dívida externa do Haiti saltou para U\$ 115,5 milhões, em 1975, alcançando a casa dos U\$ 
269,5 milhões, em 1980 (HAITI..., 2010)4. Ou seja, um aumento de quase $1.000 \%$ em menos de dez anos.

Para pagar essa dívida, o governo haitiano se viu obrigado a recorrer aos empréstimos de instituições financeiras internacionais como Fundo Monetário Internacional (FMI) e Banco Mundial. E, dentre as contrapartidas exigidas para a concessão destes empréstimos, estava a flexibilização das políticas alfandegárias e a redução das taxas de importação. Em outras palavras, a abertura em definitivo do mercado haitiano para os produtos estrangeiros.

Foi esta entrada desenfreada de produtos estrangeiros no mercado nacional o motivo principal para que o Haiti perdesse a autossuficiência na produção de cereais a partir de 1972. Os camponeses e a produção agrícola haitiana não tinham condições de competir com as mercadorias importadas, que eram vendidas a preços mais baixos devido aos subsídios governamentais que recebiam em seus países de origem.

O caso mais emblemático desta situação é o da produção nacional de arroz, que entrou em colapso com a chegada do "arroz de Miami”, como ficou conhecido o arroz importado dos Estados Unidos.

Em 1985, das 170 mil toneladas de arroz consumidas pela população haitiana, 163 mil eram produzidas no Haiti e apenas sete mil eram importadas. Em 1990, com a chegada do "arroz de Miami" no país, do total de 228 mil toneladas consumidas, 116 mil eram nacionais e 112 mil importadas. Já em 1995, no auge do Neoliberalismo, das 281 mil toneladas consumidas, apenas 89 mil foram produzidas no país, enquanto 192 mil vieram de fora. Até que, em 2010, com a importação de 329 mil toneladas, o equivalente a $90 \%$ de todo o consumo nacional, o Haiti se transformou no quarto maior importador de arroz dos EUA5

Com a queda da Ditadura dos Duvalier no final da década de oitenta, configura-se, no Haiti, um movimento de massas que busca resgatar a soberania nacional, um movimento popular que não lutava somente contra a Ditadura, mas reivindicava também mu-

\footnotetext{
${ }^{4}$ Segundo dados do Global Development Finance, External Debt of Developing Countries (GDF) (HAITI..., 2010).

${ }^{5}$ Informações coletadas no site da USA Rice Federation. Disponível em: <http:// www.usarice.com/index.php>. Acesso em: 15 maio 2012.
} 
danças substanciais no contrato social, tais como uma nova repartição da riqueza nacional, a realização da reforma agrária e o fim da marginalização do setor camponês. Foi esse movimento de massas que elegeu o padre Jean Bertrand Aristide para a presidência em 1990.

Este movimento popular que tinha reivindicações claramente antineoliberais foi duramente reprimido por meio de dois golpes de estado, em 1991 e 1994, que contaram com mais de 20.000 soldados dos Estados Unidos e toda uma estratégia de divisão, fragmentação e corrupção do movimento social com os projetos de desenvolvimento das Organizações não Governamentais (ONGs) e das agências humanitárias, como a Agência dos Estados Unidos para o Desenvolvimento Internacional (USAID).

Assim que, aproveitando a grande repressão aos movimentos sociais (estima-se que cerca de quatro mil haitianos foram mortos nesse período e mais de 12 mil militantes sociais forçados a exilar-se do país), reforçou-se a implantação do projeto neoliberal no Haiti (PATROLA; GOMES, 2010).

\section{NOVO SÉCULO, NOVAS OCUPAÇÕES}

O século XXI se inicia com uma nova eleição de Jean Bertrand Aristide para a presidência do Haiti. Diante de um governo conturbado, que tenta conjugar frágeis aspirações soberanas com os interesses neoliberais estrangeiros, a população haitiana presencia o surgimento de grupos paramilitares que, patrocinados pela Agência Central de Inteligência (CIA), iniciam o processo de desestabilização do governo. No início de 2004, ano do bicentenário da independência haitiana, Aristide é novamente deposto do poder após uma nova ocupação militar estadunidense.

A invasão dos marines é seguida pela resolução do Conselho de Segurança da Organização das Nações Unidas (ONU) que determina a criação de uma missão de estabilização do Haiti (ONU, 2004), já que o país é visto como uma ameaça para a segurança do hemisfério. Formada por soldados de 36 países, tendo o exército brasileiro à frente e contando com a presença massiva de contingentes latino-americanos, as tropas da MINUSTAH desembarcam em solo haitiano em junho de 2004. Seus objetivos se dividem em quatro 
pilares fundamentais: estabilizar o país; pacificar e desarmar os grupos guerrilheiros e rebeldes; promover eleições livres e probas, e fomentar o desenvolvimento institucional e econômico do Haiti.

Nos primeiros meses de ocupação militar, a MINUSTAH se confrontou de fato com grupos armados e sequestradores que se escondiam em bairros pobres e representavam uma ameaça para a sociedade. Esses grupos foram eliminados ou presos, tanto que, em 2010, o Haiti possuía uma média de apenas 6,9 homicídios para cada 100 mil habitantes, enquanto países vizinhos como República Dominicana e Jamaica ostentavam, respectivamente, 24,9 e 52,1 homicídios por 100 mil habitantes (UNITED NATIONS OFFICE ON DRUGS AND CRIME, 2011).

As Nações Unidas cumpriam, assim, um de seus papéis, estabilizar o país frente às ameaças dos "bandos”. Lamentavelmente, a tropas da ONU não se preocuparam em eliminar ou prender os chefes dos grupos paramilitares patrocinados pela $\mathrm{CIA}$, muito menos em garantir eleições probas e o desenvolvimento econômico do Haiti.

\section{PÓS-TERREMOTO}

O terremoto que atingiu o Haiti em 12 de janeiro de 2010, ceifando a vida de mais de trezentas mil pessoas e deixando 1,5 milhões de desabrigados, pode ser encarado como o mais recente momento-chave para evidenciar a interferência do Capitalismo internacional no (não) desenvolvimento haitiano.

“A situação do país, que já era precária antes de 12 de janeiro, se tornou insustentável depois do terremoto que abalou nossa nação, evidenciando a debilidade do Estado que não é capaz de reagir perante a condição em que o país se encontra" denunciava, em 07 de abril de 2010, a carta assinada pelos representantes dos quatro principais movimentos camponeses haitianos - Mouvman Peyizan Papay (MPP), Tèt Kole Ti Peyizan Ayisyen (TK), Kòdinasyon Rejyonal Òganizasyon Sidès (KROS) e Mouvman Peyizan Nasyonal Kongrè Papay (MPNKP) (GOMES, 2010b).

Para os movimentos camponeses, a reconstrução do país pós-terremoto deveria ser encarada como uma oportunidade de descentralização do poder e dos serviços públicos que se encontra- 
vam concentrados na capital Porto Príncipe. Para eles, “[...] a produção nacional, em especial a produção agrícola e a reforma agrária, devem ser uma prioridade no plano de reconstrução" (GOMES, 2010b).

Descentralização do poder não significava, na opinião dos movimentos camponeses, resolver um mero problema de autonomia administrativa, mas sim garantir a efetiva participação popular nas instâncias de poder e decisão. Mais do que reconstruir o país sob os mesmos moldes, a oportunidade histórica que se vislumbrava era a da refundação da nação.

Não foi o que ocorreu, infelizmente.

No dia 31 de março de 2010, o futuro do Haiti foi, mais uma vez, selado de fora, durante a Conferência Internacional de Doadores Rumo a um Novo Futuro para o Haiti, realizada na sede das Nações Unidas, em Nova Iorque. Nela, a comunidade internacional leiam-se: EUA, Canadá, União Europeia, seus bancos e instituições financeiras - definiu não só como seria a reconstrução do país depois do terremoto de 12 de janeiro, mas também estipulou a quantia e o tempo necessários para efetivá-la: U\$ 9,9 bilhões, despendidos durante cinco anos (INTERNATIONAL DONORS' CONFERENCE TOWARDS A NEW FUTURE FOR HAITI, 2010).

“As medidas urgentes para reconstruir o Haiti só serão sustentáveis se elas se tornarem a fundação para um expansivo e vibrante setor privado", defendeu o empresário estadunidense Bradley J. Horwitz, durante a Conferência Internacional de Doadores em Nova Iorque (O NOVO..., 2010).

Presidente da Trilogy International Partners, empresa multinacional que tem entre suas filiais a Voilá Comcel, segunda maior companhia de telefonia móvel haitiana, Horwitz conclamou aos doadores internacionais: "Nós precisamos que vocês vejam o setor privado como seu parceiro, que compreendem como as verbas públicas podem ser alavancadas pelos dólares privados. É claro que o que é bom para os negócios é bom para o país" (ONOVO..., 2010).

Os interesses dos doadores internacionais contaram com um fervoroso defensor em solo haitiano: a burguesia nacional. Como afirma Reginald Boulos, "[...] pela primeira vez na história do 
Haiti, um setor privado unificado e global decidiu romper com o passado e formular uma visão compartilhada e um roteiro para o desenvolvimento sustentável do país". Presidente da Câmara Nacional de Comércio e Indústria do Haiti, o médico e empresário Boulos representava o setor da sociedade haitiana que via com bons olhos as oportunidades de negócios que o terremoto de janeiro de 2010 traria. Não à toa, Boulos era um dos poucos representantes haitianos na Conferência de Nova Iorque que definiu os rumos da reconstrução haitiana (O NOVO..., 2010).

Obviamente que, para comandar uma tarefa de tamanho porte, seria preciso escolher uma pessoa que cumprisse dois requisitos básicos. O primeiro deles: possuir a confiança da comunidade internacional. E, por confiança, entenda-se aplicar sem pestanejar o que for determinado pelas instituições financeiras credoras em sua eterna missão de manter subdesenvolvidas as economias subdesenvolvidas. O segundo pré-requisito, fundamental para a tranquilidade dos doadores estrangeiros: não ser haitiano.

Foi, então, que o nome do ex-presidente estadunidense Bill Clinton foi ventilado e se tornou rapidamente incontestável. Afinal, Clinton já era Embaixador da ONU no Haiti e, por mais de uma vez, tinha demonstrado sua preocupação e empenho com o bom caminhar do Neoliberalismo na pequena ilha. Bill Clinton se tornou, então, o presidente do Conselho Provisório para a Reconstrução do Haiti (CIRH). Com isso, herdou o poder de aprovação e veto sobre toda e qualquer obra de reconstrução no país.

Mas não foi só por meio do CIRH e da Conferência de Doadores que a interferência do Capitalismo internacional se tornou evidente no processo de reconstrução pós-terremoto. Essa interferência também chegou ao campo haitiano com o Projeto Winner.

Lançado em 08 de outubro de 2009 pela USAID, o Projeto Winner ("vencedor" em inglês) propunha o investimento de 126 miIhões de dólares até 2014 para construir uma nova infraestrutura agrícola no Haiti, com o objetivo de aumentar sua produtividade. Para tanto, forneceria assistência técnica especializada, além de serviços técnicos e insumos agrícolas, como pesticidas e fertilizantes. 
A primeira grande iniciativa deste projeto foi a distribuição das 475 toneladas de sementes de milho híbrido doadas pela transnacional Monsanto aos camponeses haitianos em maio de 2010. "As sementes irão ajudar a alimentar e fornecer oportunidades econômicas para os agricultores, suas famílias e a comunidade em geral", informou à época Jean Robert Estime, diretor responsável pelo Projeto Winner (GOMES, 2010a).

Para compreender que tipo de "oportunidades econômicas" são essas, é preciso elucidar quem são os atores por trás deste Projeto.

Seu diretor responsável, Jean Robert Estime, serviu como Ministro das Relações Exteriores durante os 29 anos da Ditadura Duvalier no Haiti.

Arquiteta e coordenadora do Winner, a United States Agency for International Development (USAID) é uma agência governamental estadunidense criada em 1961. Segundo sua página oficial na Internet, tem a missão de “[...] promover os interesses da política externa dos Estados Unidos na expansão da democracia e dos mercados livres, melhorando a vida dos cidadãos do mundo em desenvolvimento". Com sede em Washington/DC, a USAID está presente nas cinco regiões do mundo. Seu trabalho apoia "[...] o crescimento econômico e os avanços da política externa dos Estados Unidos" (UNITED STATES AGENCY FOR INTERNATIONAL DEVELOPMENT, 2012).

O que não foi dito nem pela Monsanto, muito menos pelos responsáveis do projeto Winner, é que essas sementes híbridas de milho só poderiam cumprir suas promessas de produtividade e adaptação ao clima tropical haitiano se fossem tratadas com herbicidas, fertilizantes e produtos químicos específicos, que, não por acaso, são produzidos pela própria Monsanto. Isso significa que os agricultores haitianos que recebessem as sementes híbridas só conseguiriam torná-las produtivas se adquirissem os herbicidas e fertilizantes da Monsanto.

Além disso, as famílias camponesas não poderiam reaproveitar as sementes que brotarem desse milho, já que uma das características das sementes híbridas é que apenas a sua primeira geração é adequada para o plantio. Se quiserem continuar produzindo na 
próxima safra, os camponeses terão de comprar novas sementes da Monsanto. Os donatários se transformarão em clientes.

De fato, por trás do plano de reconstrução do Haiti e do projeto Winner, se esconde o avanço das multinacionais no campo haitiano, implantando um modelo de produção e distribuição agrária ainda mais concentrador que impede a reforma agrária e a possibilidade de refundação do país.

"Trata-se de um novo terremoto mais perigoso do que o que ocorreu em 12 de Janeiro", denuncia Chavannes Jean-Baptiste, coordenador do Mouvman Peyizan Papay (MPP) e membro da Via Campesina haitiana. "Não se trata de uma ameaça, mas de um ataque muito forte à agricultura camponesa, aos camponeses e às camponesas, à biodiversidade, às sementes crioulas que estamos defendendo, ao que resta de nosso meio ambiente no Haiti. Não podemos aceitar isso"(GOMES, 2010a).

\section{PARA NÃO CONCLUIR}

Diante de uma conjuntura tão perversa, o leitor pode chegar à conclusão de que não há mais nada a ser feito. Resignação ou migração são as únicas saídas possíveis para o povo haitiano. De modo algum.

A constante interferência do Capitalismo estrangeiro em conluio com setores da burguesia nacional no agravamento da dependência socioeconômica do Haiti é, de fato, uma condição objetiva que precisa ser levada em consideração por aqueles que buscam superar e transformar essa situação. Mas não é determinante, tampouco insuperável.

Afinal, não podemos menosprezar o papel que o protagonismo popular, a força da vontade humana, exerce na transformação da história. Ainda mais quando falamos do Haiti, uma nação que levou a cabo a primeira revolução de escravos vitoriosa da história, liderada por um exército de camponeses, homens, mulheres, velhos e crianças, que derrotaram as três maiores potências bélicas de sua época.

"Saímos do nada, de uma condição sub-humana, de uma massa de gente que não falava a mesma língua, que era açoitada dia e noite", relembra Gerald Mathurin (2010). "E desta condição conseguimos com destreza e com visão liberar um país e fazer a inde- 
pendência. É um ato maior na história do mundo, porque vamos colocar em cena uma raça, uma qualidade de pessoas que antes se afirmava não serem humanos".

É a partir desse arcabouço histórico que Mathurin encara a conjuntura atual do Haiti. "Estamos vivendo uma crise muito profunda. Não é uma crise setorial, é a nação mesma que está em crise. E isso é o que chamamos a Crise Haitiana de Nação. Uma crise que somente o povo haitiano pode resolver" (MATHURIN, 2010).

Para tanto, Camille Chalmers acredita que é preciso “[...] desenvolver laços de trabalho e aproximação entre o movimento camponês e outros setores do movimento social para podermos chegar a um projeto nacional viável, crível e mobilizador, que apresente uma alternativa real para o povo. Um projeto anti-imperialista, de liberação nacional, de afirmação da identidade caribenha e nacional contra todo tipo de dominação, exploração e manipulação" (CHALMERS, 2010).

A crise por que passa a sociedade haitiana é grave, não restam dúvidas. Mas não é insolúvel. Cabe aos próprios haitianos descobrir que caminhos percorrer para reconquistar a soberania nacional. Como está inscrito no túmulo de Jean Jacques Dessalines: "Ao primeiro tiro de canhão, soem o alarme. Cidades desaparecem, mas a nação permanece".

\section{REFERÊNCIAS}

ANTOINE, George Samuel. Desgraça no Haiti está sendo boa para nós aqui, diz cônsul no Brasil; assista. Folha Online, 15 jan. 2010. Entrevista a repórter Elaine Cortez. Disponível em: <http:// www1.folha.uol.com.br/folha/mundo/ult94u679672.shtml>. Acesso em: 15 maio 2012.

BANDITS or Patriots?: Documents of Charlemagne Péralte, National Archives. Translation by Elena an Kirill Razlogova. [1919]. Disponível em: <http://historymatters.gmu.edu/d/4946/>. Acesso em: 16 maio 2012 (Tradução nossa).

CASTOR, Suzy. Campesinato haitiano: su pontencial revolucionário. In: CASANOVA, Pablo González (Org.). Historia política de los campesinos latinoamericanos. México: Siglo XXI Editores, 1984. v.1. 
- A Transição Haitiana: entre os perigos e a esperança. In: SADER, E. (Coor.). Cadernos de Pensamento Crítico Latino-americano. São Paulo: Expressão Popular; Buenos Aires: CLACSO, 2008. v. 2, p. 11-24. (Coleção Cadernos de Pensamento Crítico Latino-americano).

CAUVIN, Nicole Xavier. Haiti: a sociological analysis of the agrarian reforms of 1804. 1975. Tese (Doutorado em Filosofia) - The Graduate Scholl of Arts and Science, New York University, Nova Iorque, 1975.

CHALMERS, Camille. Nosso futuro depende de uma ruptura total com todas as formas de dependência. 17 set. 2010. Entrevistadores: Oelington de Souza, Paulo Almeida e Thalles Gomes. Entrevista concedida ao Jornal Brasil de Fato e publicada no site da Agência Latinoamericana de Información (ALAI). Disponível em: <http:// alainet.org/active/40967\&lang=es>. Acesso em: 15 maio 2012.

GOMES, Thalles. Monsanto e o Projeto Vencedor no Haiti. América Latina en Movimiento, Quito, 19 maio 2010a. Disponível em: <http://www.alainet.org/active/38266>. Acesso em: 15 maio 2012.

- Alagoas e Haiti, duas faces de uma mesma tragédia. In: MOVIMENTO dos Atingidos por Barragens, 23 jun. 2010b. Disponível em: <http://www.mabnacional.org.br/artigo/alagoas-e-haiti-duas-faces-uma-mesma-trag-dia>.

. As duas repúblicas do Haiti. Revista Fórum, 21 abril $2010 b$. Disponível em: <http://revistaforum.com.br/blog/2010/04/as duas_republicas_do_haiti/>. Acesso em: 15 maio 2012.

HAITI - external debt stocks: external debt stocks, concessional (DOD, current US\$). [2010]. Segundo dados do Global Development Finance, External Debt of Developing Countries (GDF). Disponível em: <http://www.indexmundi.com/facts/haiti/external-debt-stocks>. Acesso em: 15 maio 2012.

INTERNATIONAL DONORS' CONFERENCE TOWARDS A NEW FUTURE FOR HAITI, Nova York, 31 mar. 2010. Final Comumuniqué. Nova York: 31 mar. 2010. Disponível em: <http://www.haiticonference.org/communique.html>. 
JAMES, C.L.R. Os Jacobinos negros: Toussaint L'Ouverture e a revolução de São Domingos. São Paulo: Boitempo, 2000.

JOHNSON, James Weldon. Self-determining Haiti: four articles reprinted from The Nation embodying a report of an investigation made for The National Association for the Advancement of Colored People. Berkeley: University of Carlifonia, 1920.

LOUIS-JUSTE, Jn Anil. ONG: Ki gouvènman ou ye? Porto Príncipe: Asosyasyon Inivèsitè ak Inivèsitèz Desalinyèn, 2009.

MARINI, Ruy Mauro. Subdesarrollo y revolucion. 5. ed. México: Siglo XXI Editores, 1974.

MATHURIN, Gerald. Gerald Mathurin: a crise haitiana de nação. 20 jul. 2010. Entrevistadores: José Luis Patrola e Thalles Gomes. Entrevista concedida ao Jornal Brasil de Fato e publicada no site da Agência Latinoamericana de Información (ALAI). Disponível em: <http://alainet.org/active/39663\&lang=es>. Acesso em: 15 maio 2012.

O NOVO futuro do Haiti. Brasil de Fato, São Paulo, 27 abr. 2010.

ONU. Security Counciul. Resolution 1542 (2004). Adopted by the Security Counciul at its 4961st meeting, on 30 April 2004. 30 abr. 2004. Disponível em: <http://www.un.org/ga/search/view_doc. asp?symbol=S/RES/1542(2004)\&referer=http://www.un.org/en/peacekeeping/missions/minustah/\&Lang=E >. Acesso em: 15 maio 2012.

PATROLA, José Luis; GOMES, Thalles. Tropas de desestabilização. América Latina en Movimiento, Quito, n. 461, p. 18-21, dic. 2010.

UNITED NATIONS OFFICE ON DRUGS AND CRIME. 2011 Global Study on Homicide: trends, contexts, data. Viena, 2011. p. 95. The 2011 Global Study on Homicide was prepared by the Statistics and Surveys Section under the supervision of Sandeep Chawla, Director, Division for Policy Analysis and Public Affairs. Disponível em: <http://www.unodc.org/documents/southerncone// noticias/2011/10-outubro/Globa_study_on_homicide_2011_web. pdf>. Acesso em: 15 maio 2012.

UNITED STATES AGENCY FOR INTERNATIONAL DEVELOPMENT. Who we are. 2012. Disponível em: <http://www.usaid.gov/who-we-are >. Acesso em: 15 maio 2012. 